\title{
Simulation of static stress distribution of wheat piles in silos by the modified Cam-clay model $* *$
}

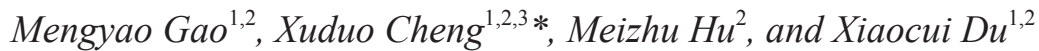 \\ ${ }^{1}$ College of Food Science and Engineering, Nanjing University of Finance and Economics, Nanjing, China \\ ${ }^{2}$ Collaborative Innovation Center for Modern Grain Circulation and Safety, Nanjing, China \\ ${ }^{3}$ Department of Food Science and Engineering, Nanjing University of Finance and Economics, 3 Wenyuan Road, Nanjing 210046, \\ Jiangsu Province, China
}

Received August 13, 2017; accepted January 5, 2018

\begin{abstract}
Static stress of granular materials stored in silos is important for the security of materials during storage. Janssen equation was commonly used to calculate the static stress of grains in silos, but later researchers found the equation underestimated loads in storage bins. In this paper, the modified Cam-clay model was applied to study the stress distribution of wheat piles at four moisture levels, stored in a circular flat bottom silo, at different grain depth and radius of silos. The results showed that as the grains depth increased, the vertical stress of wheat piles increased except the wall-bottom of silos, and the lateral stress increased except the center of silos near bin bottom. Moreover, it was found that as the radius increased, the vertical stress of wheat piles decreased at the same depth and moisture content, and the lateral stress decreased but increased near the bin bottom in the same case. When the mean stress of a layer of grains were observed, it was found that the lateral stress was negatively correlated with moisture content when the vertical stress had no concern with it at the same grain depth and all of them approached the maximum at the same moisture content.

Keywords: stress distribution, wheat pile, silo, modified Cam-clay model, finite element method
\end{abstract}

\section{INTRODUCTION}

Wheat is an important commercial crop and a major source of food with worldwide production of $672 \mathrm{Mt}$ in 2012 (FAOSTAT, 2014). China, as the largest producer and consumer of wheat in the world (He et al., 2001), has a wheat production of $100 \mathrm{Mt}$ per year in recent years. Due to the large production and China's grain storage policy,

\footnotetext{
*Corresponding author e-mail: chengxuduo@hotmail.com

**This work was supported by the National Nature Science Foundation of China project No. 31371865, funded by the Priority Academic Program Development of Jiangsu Higher Education Institutions (PAPD) (2015-2020).
}

a majority of the wheat is stored for an average of three years (Li et al., 2011), longer than the common storage time in developed countries. Therefore, safe storage of wheat piles in the silo is of great importance.

During storage, wheat grains are undergoing various forces such as gravity loading, internal friction and the force against from the wall of silos (Thompson and Ross, 1983) that result in the difference of pressure at different depth in silos. The static stresses of materials stored in silos are significant for the design of grain storage systems for the accuracy of calculations of these stresses is directly related to the safety, reliability and economy of the storage systems. For predicting the static pressure of stored material in bins, Janssen (1895) proposed a classical theory. The theory proposed an equation to calculate the static vertical and horizontal stresses in granular material stored in cylindrical silos by micro layer balance principle, and it has considered the wall friction effect. But it was found that the assumption of constant bulk density, which is commonly used by Janssen equation, caused the underestimations of loads in storage bins (Haque, 2013; Roberts, 1998).

Later analytical methods of the lateral and vertical stress were proposed by many authors (Drescher and Vgenopoulou, 1985; Hatfield and Bartali, 1988; Lvin, 1971) in order to improve the accuracy of predictions made by the Janssen equation (1895). In the latter of 20th century, finite element method (FEM) was increasingly applied by many international scholars to study the stress of granular materials in silos because of the improvement of computer

(C) 2019 Institute of Agrophysics, Polish Academy of Sciences 
technology. This scientific-based numerical technology can contribute to a safer and more economic design of silos and the prevention of failure. Most research works mainly focused on the stress distribution of stored material during filling or discharge (Goodey et al., 2017; Vidal et al., 2008; Yin et al., 2014). Several researchers have investigate the static stress distribution of material stored in silos. Jofriet et al. (1977) applied the linear elastic model by using FEM to study the static stress distribution of material stored in silos, and Mahmoud and Abdel-Sayed (1981) estimated the static pressure of the wall of circular silo with elastic corrugated plate by the FEM which applied a nonlinear hyperbolic constitutive equation. Bishara et al. (1983) applied a nonlinear elastic model to estimate the static pressure of the wall of a concrete silo.

However, the grain when compressed has two deformation stages, including the elastic deformation stage and the plastic deformation stage. Moreover, wheat grain was soft and the void of wheat piles was large, which caused the volume easy to shrink when compressed. The volume changes was the compression of volume, called the volume strain. But the constitutive equation chosen above has neglected the volume changes in the plastic deformation stage. The calculated results underestimated the value of stress distribution. The modified Cam-clay (MCC) model had fully considered the volume compression of the material, so in this study, we applied the MCC model by using ABAQUS to calculate the static stress of different depth, radius and moisture content of wheat piles in a steel flat bottom silo.

\section{MATERIALS AND METHODS}

Wheat for experiment, Yannong 20, was produced in Suzhou, China, which was manually picked to remove the broken and immature grains. The initial moisture content was $12.66 \%$ w.b. The moisture contents of the wheat were firstly adjusted to four different moisture of 10.60, 12.66, 14.22 and $16.13 \%$ w.b., for the common range of moisture content of wheat was from 10 to $16 \%$ w.b., then stored in plastic bags at approximately $4^{\circ} \mathrm{C}$. The moisture content of wheat grains was determined by using a standard ovendrying method to dry $10 \mathrm{~g}$ samples at $130^{\circ} \mathrm{C}$ for $19 \mathrm{~h}$ in triplicate (ASAE Standards, 2001).

In the process of stress simulations of wheat piles in silos, we firstly assumed the wheat pile with four moisture levels above was stored in the model silo, and then an appropriate elastoplastic constitutive model was used for describing the relationship of stress-strain of these grains. Finally, this selected model was applied to calculate the bulk density and stress distribution of wheat piles at different moisture content by using ABAQUS.

In the elastoplastic mechanics, the researchers constructed a lot of constitutive models (Zhang et al., 1986), such as Mohr-Coulomb, Drucker Prager, Lade Duncan and MCC model. All of these models' yield surfaces, including
Mohr-Coulomb, Drucker Prager and Lade Duncan models, are called shear yield surfaces. These models can reflect compressive rigidity and dilatancy of the grain, but not the static pressure yield.

The MCC model is a basic constitutive model (Suebsuk et al., 2010; Tripodi et al., 1994), which provides adequate results for predicting material behavior in conventional triaxial tests as well as in consolidation analysis. The yield surface of MCC model is the equivalent surface of plastic volume strain. The model can reflect the compressive rigidity, shear shrinkage and static pressure yield of the grain, also can reflect the change of mean normal stress not only causes the increment of plastic volume strain, but also the increment of plastic shear strain. Meanwhile, the change of shear stress will not only causes the increment of plastic shear strain, but also the increment of plastic volume strain. For the grain, the volume strain when compressed is dominating because of its large void and soft texture, the MCC model has fully considered the volume strain of the grain, and the model only has five parameters which are easily determined by conventional triaxial tests, so it more suitable for studying the stress-strain relationship of wheat piles.

In the MCC model, the total strain increment $d \varepsilon$ due to a stress $d \sigma$ is divided into two components: the volume strain increment $d \varepsilon_{v}$ and the shear strain increment $d \varepsilon_{S}$, as follows:

$$
d \varepsilon=d \varepsilon_{v}+d \varepsilon_{S}
$$

The volume strain increment $d \varepsilon_{v}$ and the shear strain increment $d \varepsilon_{S}$ can be written in the following form:

$$
\begin{aligned}
& d \varepsilon_{v}=d \varepsilon_{v}^{e}+d \varepsilon_{v}^{p}, \\
& d \varepsilon_{s}=d \varepsilon_{s}^{e}+d \varepsilon_{s}^{p},
\end{aligned}
$$

where: $d \varepsilon_{v}^{e}$ is the elastic volumetric strain increment; $d \varepsilon_{s}^{e}$ is the elastic shear strain increment; $d \varepsilon_{v}^{p}$ is the plastic volumetric strain increment; $d \varepsilon_{s}^{p}$ is the plastic shear strain increment.

In the MCC model, the generalized shearing force $q$ and the mean principal stress $p$ can be represented as follows:

$$
\begin{gathered}
q=\sigma_{1}-\sigma_{3}, \\
p=\frac{\left(\sigma_{1}+2 \sigma_{3}\right)}{3},
\end{gathered}
$$

where: $\sigma_{1}$ is the axial pressure $(\mathrm{kPa}), \sigma_{3}$ is the confining pressures $(\mathrm{kPa})$.

The elastic strain increment is calculated using generalized three dimensional Hooke's law. So the elastic strain increment can be expressed as follows:

$$
d \varepsilon_{v}^{e}=\frac{3(1-3 \nu)}{E} d p
$$




$$
\begin{aligned}
& d \varepsilon_{s}^{e}=\frac{2(1+\nu)}{3 E} d q, \\
& E=\frac{3(1-2 v)(1+e)}{\kappa} p .
\end{aligned}
$$

Bring formula (8) into Eqs (6) and (7), get the following equations:

$$
\begin{gathered}
d \varepsilon_{v}^{e}=\frac{\kappa}{1+e} \frac{d p}{p}, \\
d \varepsilon_{s}^{e}=\frac{2}{9} \frac{1+v}{1-2 v} \frac{\kappa}{1+e} \frac{d q}{p},
\end{gathered}
$$

where: $v$ is the Poisson's ratio, dimensionless; $\kappa$ is the isotropic swelling index, dimensionless; $e$ is the void ratio, dimensionless; $E$ is the elastic modulus, $\mathrm{kPa}$.

The plastic stress-strain relationship (Gong, 1999; Chen et al., 2011) in the MCC model is shown as the following form:

$$
\begin{aligned}
& d \varepsilon_{v}^{p}=\frac{\lambda-\kappa}{1+e}\left[\frac{M^{2}-\eta^{2}}{M^{2}+\eta^{2}} \frac{d p}{p}+\frac{2 \eta}{M^{2}+\eta^{2}} \frac{d q}{p}\right], \\
& d \varepsilon_{s}^{p}=\frac{\lambda-\kappa}{1+e}\left(\frac{2 \eta}{M^{2}+\eta^{2}}\right)\left[\frac{d p}{p}+\frac{2 \eta}{M^{2}-\eta^{2}} \frac{d q}{p}\right],
\end{aligned}
$$

where: $\eta=q / p$, dimensionless, $M$ is the critical state ratio, dimensionless, $\lambda$ is the logarithmic hardening modulus, dimensionless.

According to the classical elastic-plastic theory, we can obtain the explicit expression of the elastic-plastic matrix of the MCC model. The constitution stress-strain equation (Luo et al., 2010) can be written in an incremental form as follows:

$$
\begin{gathered}
\left\{\begin{array}{l}
\mathrm{d} p \\
\mathrm{~d} q
\end{array}\right\}=\left[C^{e p}\right]\left\{\begin{array}{l}
\mathrm{d} \varepsilon_{v} \\
\mathrm{~d} \varepsilon_{s}
\end{array}\right\}, \\
{\left[C^{\mathrm{ep}}\right]=\left[\begin{array}{ll}
C_{p p} & C_{p q} \\
C_{q p} & C_{q q}
\end{array}\right],} \\
C_{p p}=K \frac{p\left(M^{4}-\eta^{4}\right)+12 \frac{\lambda-\kappa}{1+e} G \eta^{2}}{p\left(M^{4}-\eta^{4}\right)+\frac{\lambda-\kappa}{1+e} K\left(M^{2}-\eta^{2}\right)^{2}+12 \frac{\lambda-\kappa}{1+e} G \eta^{2}}, \\
C_{p q}=C_{q p}=\frac{-6 \frac{\lambda-\kappa}{1+e} K G \eta\left(M^{2}-\eta^{2}\right)}{p\left(M^{4}-\eta^{4}\right)+\frac{\lambda-\kappa}{1+e} K\left(M^{2}-\eta^{2}\right)^{2}+12 \frac{\lambda-\kappa}{1+e} G \eta^{2}}, \\
C_{q q}=\frac{3 G\left[\left(M^{4}-\eta^{4}\right) p+K \frac{\lambda-\kappa}{1+e}\left(M^{2}-\eta^{2}\right)^{2}\right]}{p\left(M^{4}-\eta^{4}\right)+\frac{\lambda-\kappa}{1+e} K\left(M^{2}-\eta^{2}\right)^{2}+12 \frac{\lambda-\kappa}{1+e} G \eta^{2}},
\end{gathered}
$$

where, $K=\frac{E}{3(1-2 v)}$ is bulk modulus $(\mathrm{kPa}), G=\frac{E}{2(1+v)}$ is shear modulus $(\mathrm{kPa})$.

From the above formulae, the parameters of the MCC model contains $M, \lambda, \kappa, E$ and $\nu$.

For this study the model silo which established by ABAQUS was a thin-walled, flat bottom and cylindrical steel bin with $10 \mathrm{~m}$ in diameter and 31 meters in height. The elastic property of the silo with Young's modulus was $2.1 \times 10^{8} \mathrm{kPa}$ and Poisson's ratio was 0.30 (Ayuga et al., 2002, 2006), and the modeling space of the silo and stored wheat grains were designed to be axisymmetric because the volume of the wheat pile was axisymmetric.

Modified Cam-clay model parameters of wheat samples is a significant part of the calculations. The MCC model comprised five parameters: the critical state ratio $M$ (slope of critical-state line), the logarithmic hardening modulus $\lambda$ (slope of loading path), the isotropic swelling index $\kappa$ (slope of unloading path), the initial bulk density $\rho_{0}$ and the initial void ratio $e_{0}$. Each parameter of the MCC model was determined for each level of the moisture content. The TSA-6A triaxial apparatus instrument (Fig. 1) which consisted of a confining pressure control system, an axial loading system, a displacement recorder, a dynamometer, a pressure chamber and a volumeter, was used to conduct the conventional triaxial tests.

The LKY-1 grain porosity instrument (Nanjing Soil Instrument Co., Ltd, China) was used to measure the porosity of wheat piles (Fig. 1).

$$
e=\frac{V_{\text {void }}}{V_{\text {solid }}}=\frac{V-V_{0}\left(1-\varepsilon_{0}\right)}{V_{0}\left(1-\varepsilon_{0}\right)},
$$

where: $V$ is the sample volume (obtained by the isotropic consolidation tests) $\left(\mathrm{m}^{3}\right), V_{\text {void }}$ is the void volume of the sample $\left(\mathrm{m}^{3}\right), V_{\text {solid }}$ is the volume of the sample particles $\left(\mathrm{m}^{3}\right), \varepsilon_{0}$ is the initial porosity of the sample; $V_{0}$ is the initial volume of the sample $\left(\mathrm{m}^{3}\right)$.

The critical state ratio $M$ was determined by the axial compression tests (Rooda and Haaker, 1977; Smith, 1981). In the axial compression test, the confining pressures $\sigma_{3}$ $(30,50,70,90,110 \mathrm{kPa})$ were applied in the pressure chamber controlled by the confining pressure control system. A very slow shear strain rate, $1.000 \mathrm{~mm} \mathrm{~min}^{-1}$, was used to minimize the retardation time effect. The dynamometer reading and the volume reduction of sample were recorded for each $0.4 \mathrm{~mm}$ increased in vertical displacement of the sample until a peak reading occurred in the dynamometer. The dynamometer reading was called the principal stress difference $\sigma_{1}-\sigma_{3}$. The above axial compression tests were repeated three times at every confining pressure. Parameter $M$ was the slope of the critical-state line as plotted in $q v s$ $p$ space (Fig. 2).

The logarithmic hardening modulus $\lambda$ and the isotropic swelling index $\kappa$ were determined by the isotropic consolidation tests (Tripodi et al., 1994). Parameter $\lambda$ and $\kappa$ were 

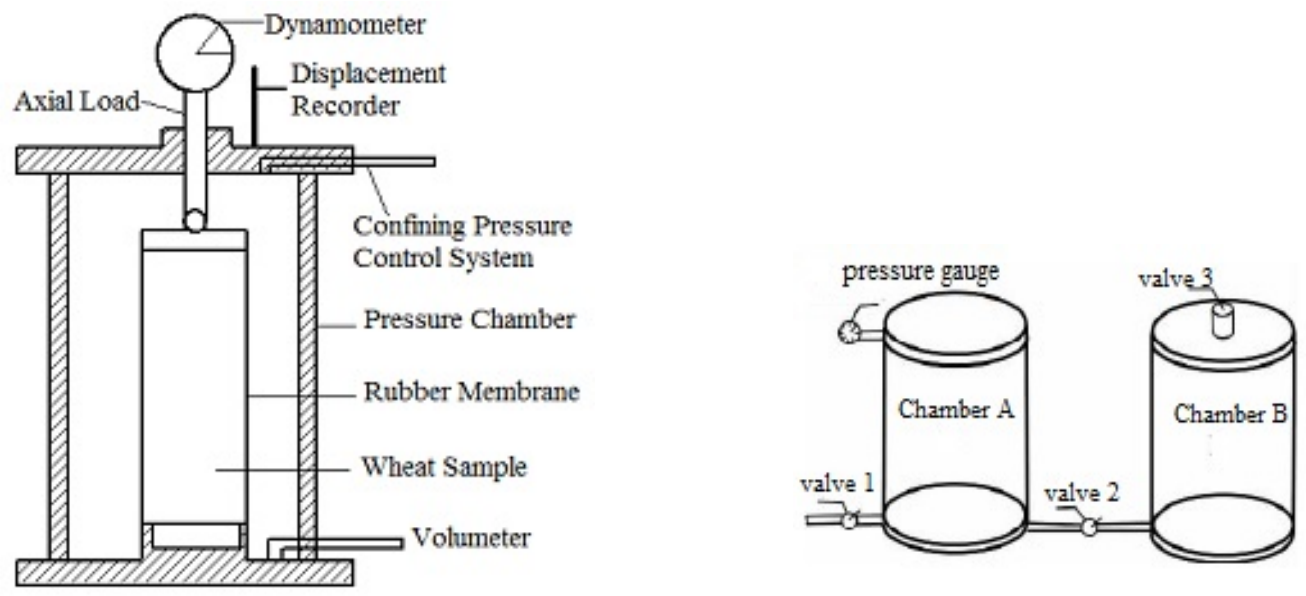

Fig. 1. Schematic illustration of TSA-6A triaxial apparatus (left) and LKY-1grain porosity instrument (right).
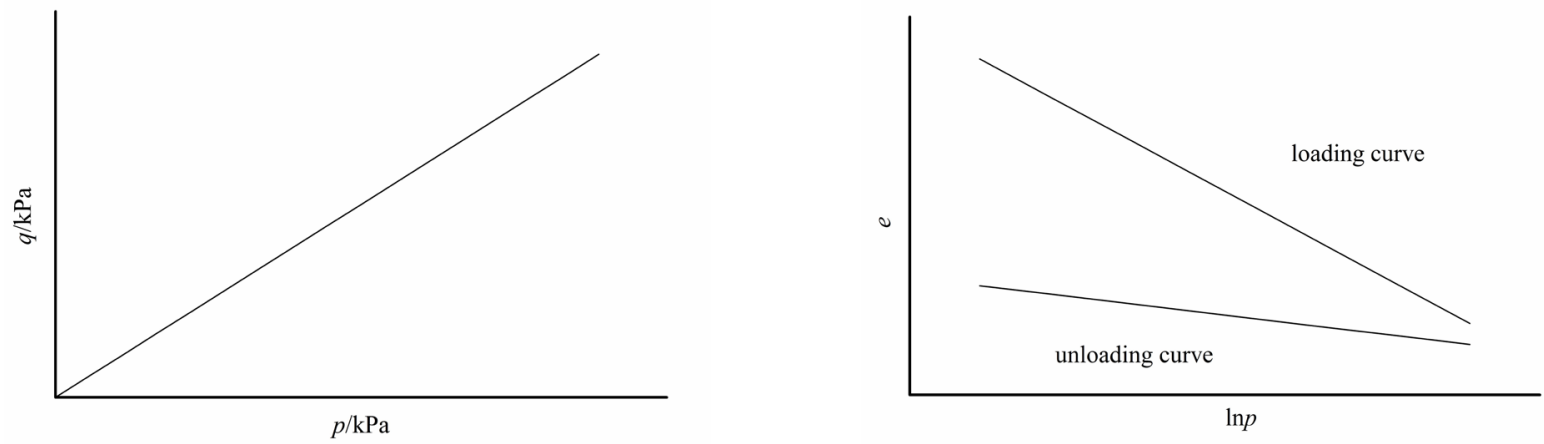

Fig. 2. Critical state curve (left) and graphical determination of $\lambda$ and $\kappa$ (right).

the slopes of loading and unloading curve plotted in e vs $\ln p$ graph (Fig. 2). The void ratio $e$ of the wheat pile at different confining pressure can be calculated by Eq. (18).

In the process of loading, the confining pressure $\sigma_{3}$ increased from 0 to $200 \mathrm{kPa}$ and the volume reduction of sample was recorded for each $5 \mathrm{kPa}$ increment of confining pressure. In the process of unloading, the volume increment of sample was recorded for each $5 \mathrm{kPa}$ decreased in confining pressure which $\sigma_{3}$ decreased from 200 to $0 \mathrm{kPa}$. Each test repeated three times to reduce the contingency of experiment.

In the actual storage process, a friction occurred between the wheat pile stored in silos and the wall of silos. For this research, the friction was described by a simple Coulomb friction model (with penalty friction formulation as described by Hibbitt, Karlsson and Sorenson (2001) with friction coefficient $\mu$ set to be 0.30 estimated from the research of Cheng et al. (2012) which $\mu$ between the wheat and steel was $0.25-0.63$.

During the FE analysis, the wheat pile and the silo were meshed with a 2D solid element and the element was defined by 6 horizontal nodes and 30 vertical nodes, and the element type of these parts was CAX4 (4-node bilinear axisymmetric quadrilateral). Body force was selected as the load type determined by the initial bulk density of the wheat pile.

\section{RESULTS}

The initial (uncompressed) bulk density measured (before applying the pressure on the top surface) ranged from 801.75 to $755.65 \mathrm{~kg} \mathrm{~m}^{-3}$ when the moisture content increased from 10.60 to $16.13 \%$ w.b. The similar observations of lower densities at higher moisture contents were reported by other researchers (Thompson and Ross, 1983). The initial void ratio was calculated by Eq. (18) when the $V$ was equal to $V_{0}$. Measured and calculated parameters of the MCC model were shown as Table 1.

The wheat pile was $30 \mathrm{~m}$ high in the silo and the samples in cylindrical silos were equally divided into thirty small circular thin layers and five radial columns, for a total of one hundred and fifty units. Vertical stress and lateral stress of wheat piles were obtained directly by ABAQUS.

The vertical and lateral stress were determined for grain of 10.60, 12.66, 14.22, 16.13\% w.b. moisture content at the radius of $0,1,2,3,4,5 \mathrm{~m}$ in the grain depth of 2 , 10, 18, and $26 \mathrm{~m}$, respectively (Fig. 3a). As the wheat pile depth increased, the vertical stress of wheat piles at every moisture content increased but decreased near the wallbottom of the silo, and the lateral stress of wheat piles increased but decreased near the center of the bin bottom. 
Table 1. Modified Cam-clay model parameters for different moisture content of the wheat pile

\begin{tabular}{|c|c|c|c|c|c|}
\hline $\begin{array}{l}\text { Moisture content } \\
\text { \% w.b. }\end{array}$ & $M$ & $\lambda$ & $\kappa$ & $e_{0}$ & $\rho_{0}$ \\
\hline 10.60 & $\begin{array}{c}1.0539 \\
(0.0092)^{*}\end{array}$ & $\begin{array}{c}0.0547 \\
(0.0010)\end{array}$ & $\begin{array}{c}0.0377 \\
(0.0013)\end{array}$ & $\begin{array}{c}0.7821 \\
(0.0002)\end{array}$ & $\begin{array}{l}801.75 \\
(0.49)\end{array}$ \\
\hline 12.66 & $\begin{array}{l}1.0368 \\
(0.013)\end{array}$ & $\begin{array}{c}0.0575 \\
(0.0001)\end{array}$ & $\begin{array}{c}0.0384 \\
(0.2000)\end{array}$ & $\begin{array}{c}0.7976 \\
(0.0002)\end{array}$ & $\begin{array}{l}801.75 \\
(0.58)\end{array}$ \\
\hline 14.22 & $\begin{array}{c}1.0064 \\
(0.0130)\end{array}$ & $\begin{array}{c}0.0661 \\
(0.0009)\end{array}$ & $\begin{array}{c}0.0429 \\
(0.0003)\end{array}$ & $\begin{array}{c}0.8322 \\
(0.0014)\end{array}$ & $\begin{array}{l}770.47 \\
(1.21)\end{array}$ \\
\hline 16.13 & $\begin{array}{c}1.0734 \\
(0.0290)\end{array}$ & $\begin{array}{c}0.0833 \\
(0.0013)\end{array}$ & $\begin{array}{c}0.0562 \\
(0.0018)\end{array}$ & $\begin{array}{c}0.8967 \\
(0.0043)\end{array}$ & $\begin{array}{c}755.65 \\
(1.11)\end{array}$ \\
\hline
\end{tabular}

*Values in the parenthesis are standard deviation of three measurements.

It was showed the vertical stress and the lateral stress of $10.60,12.66,14.22,16.13 \%$ w.b. moisture content at the radius of $0,1,2,3,4$, and $5 \mathrm{~m}$ in the grain depth of 2 , 10,18 , and $26 \mathrm{~m}$ (Fig. 3b), respectively. The vertical stress of wheat piles decreased with the increase of radius at the same moisture content and the same grain depth. As the radius increased, the lateral stress of wheat piles decreased at the grain depth of 2,10 , and $18 \mathrm{~m}$, but increased at the grain depth of $26 \mathrm{~m}$ at the same moisture content.

The mean stress of a layer of wheat piles at the same layer was calculated by an equation as:

$\overline{p_{n}}=\frac{\pi R_{1}^{2} h_{n 1} p_{n 1}+\pi\left(R_{2}^{2}-R_{1}^{2}\right) h_{n 2} p_{n 2}+\cdots+\pi\left(R_{6}^{2}-R_{5}^{2}\right) h_{n 6} p_{n 6}}{\pi R_{1}^{2} h_{n 1}+\pi\left(R_{2}^{2}-R_{1}^{2}\right) h_{n 2}+\cdots+\pi\left(R_{6}^{2}-R_{5}^{2}\right) h_{n 6}}$,

where: $\overline{p_{n}}$ is the mean stress of $n$th layer wheat piles $(\mathrm{kPa})$, $p_{n m}$ is the stress of $n m$ th unit wheat pile $(\mathrm{kPa}), h_{n m}$ is the height of $\mathrm{nm}$ th unit (m).

The mean vertical and lateral stress of different grain depth of the wheat pile at different moisture contents were shown in Fig. 4.

The mean vertical and lateral stress of wheat piles at the same moisture content increased as the wheat pile depth increased. The rate of increase was higher at smaller depth and reached the maximum of stress.

When the calculated data of mean stress of a layer of grains were observed (Fig. 5), it was found that the lateral stress was negatively correlated with moisture content when the vertical stress had no concern with it at the same grain depth and all of them approached a plateau value with increasing grain depth at the same moisture content.

\section{DISCUSSION}

From the results given, as the wheat pile depth increased, it was found the vertical edge stress of wheat piles at every moisture content increased but decreased near the wall-bottom of the silo, and the lateral stress of wheat piles increased but decreased near the center of the bin bottom. That probably because materials stored in silos slid down along the wall of silos and was subjected to upward friction (shear stress) which increased as the grain depth increased. As the grain-wall friction increased, more vertical pressure was transferred to the wall and the principal stress line (Fig. 5) gradually deviated to the wall of silos (Walters, 1973). According to the shear stress mutual equal theory, we have known that the lateral shear stress would gradually increase along the horizontal section, which caused the lateral stress was non-uniform at the section. In another word, Fig. 4 showed directly that the principal stress line did not deviate at the center of the silo which caused the vertical stress of the wheat pile at the center always increased. However, when the wheat pile was closer to the wall, the vertical stress became smaller and the lateral stress became greater. Especially at the wall-bottom of silos, the deviation degree of the principal stress line was the largest which caused the vertical stress decreased drastically, but the lateral stress still increased.

For the analysis of the variation of the stress and radius, the vertical and lateral stress had a different trends with increasing radius. The vertical stress of wheat piles decreased with the increase of radius at the same moisture content and the same grain depth. Su (1997) pointed that the vertical friction between the storage materials was zero at the center axis of the silo and varied linearly along the radius of the silo. As the grain-wall friction increased, more vertical pressure was transferred to the wall, resulting the decrease of the vertical stress of wheat piles with the increase of the radius of silos. As the radius increased, the lateral stress of wheat piles decreased at the grain depth of 2,10 , and $18 \mathrm{~m}$, but increased at the grain depth of $26 \mathrm{~m}$ at the same moisture content. This was probably due to the fact that both the effect of friction of the wall and the floor caused the largest of the deviation degree of the principal stress line at the wall-bottom of silos, which caused the lateral stress of wheat piles to increase.

The mean vertical and lateral stress of wheat piles at the same moisture content increased as the wheat pile depth increased. Du et al. (2017) proposed a model to study the 
a

$10.60 \%$ w.b.
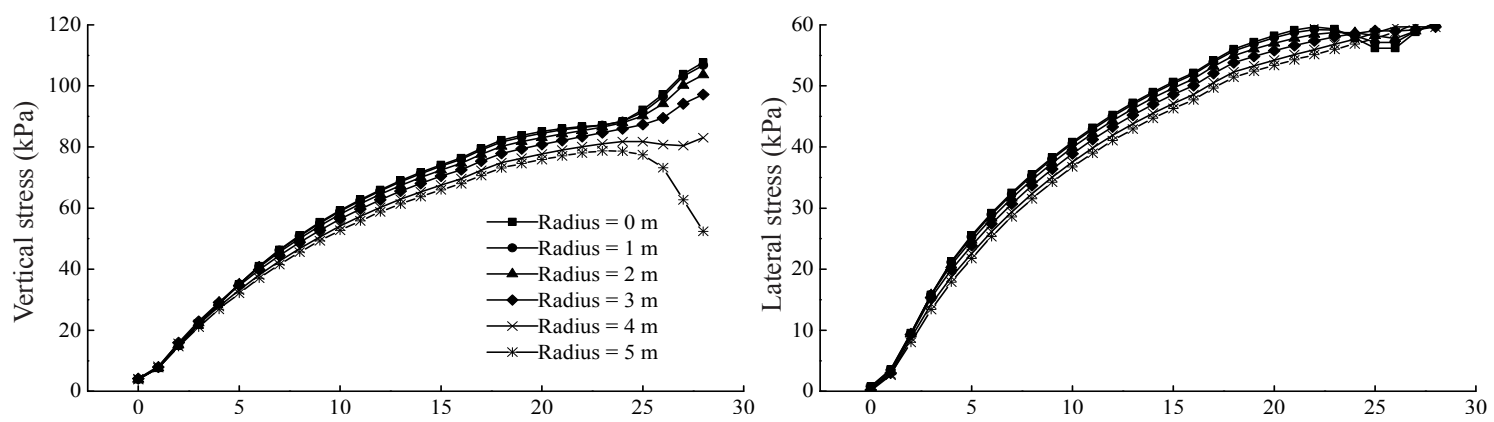

$12.66 \%$ w.b.
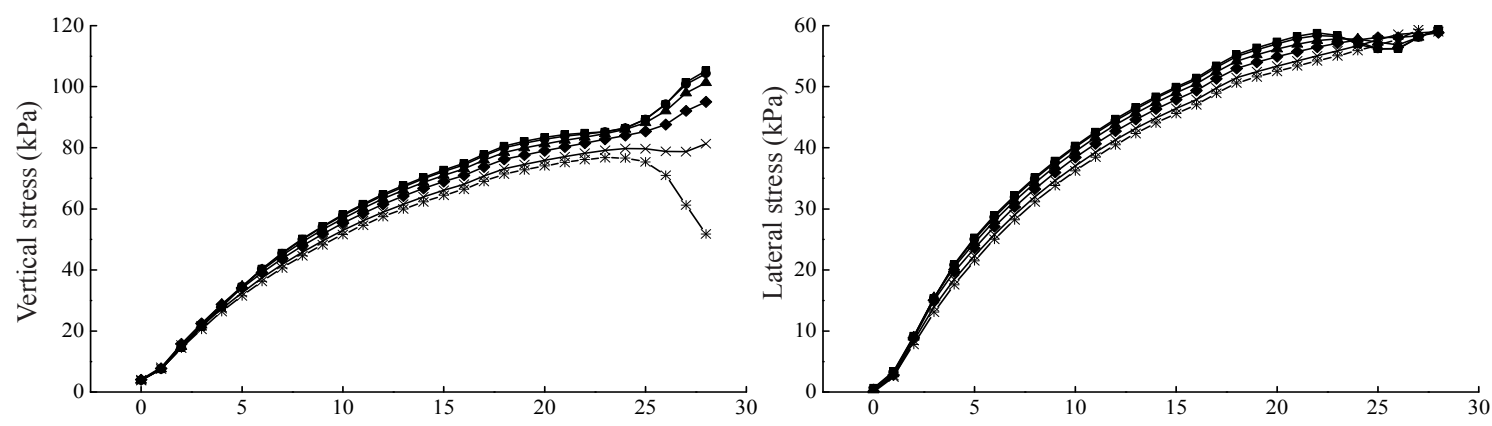

$14.22 \%$ w.b.
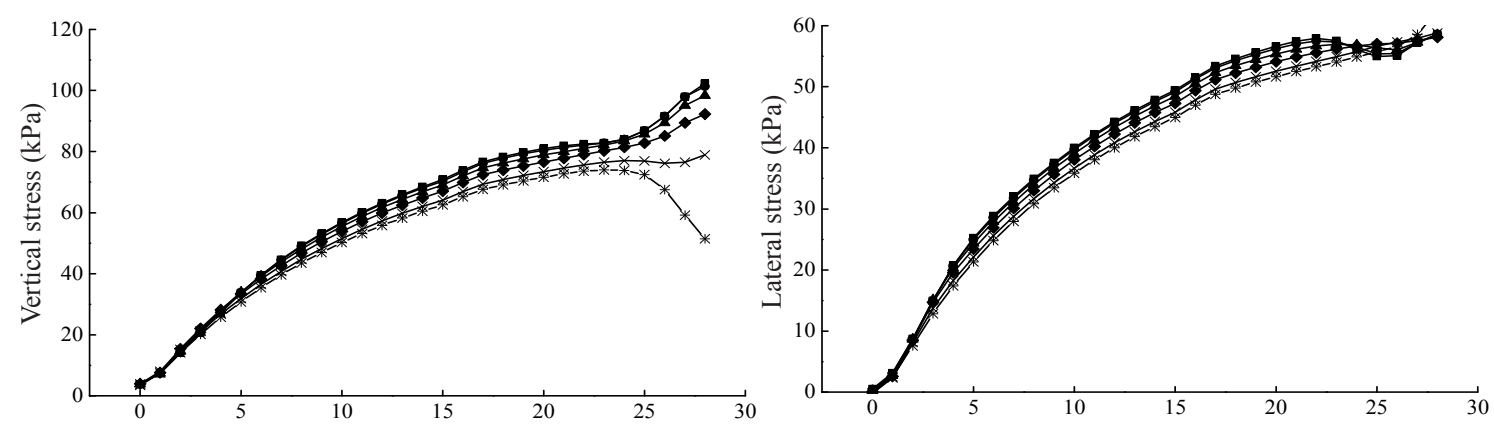

$16.13 \%$ w.b.
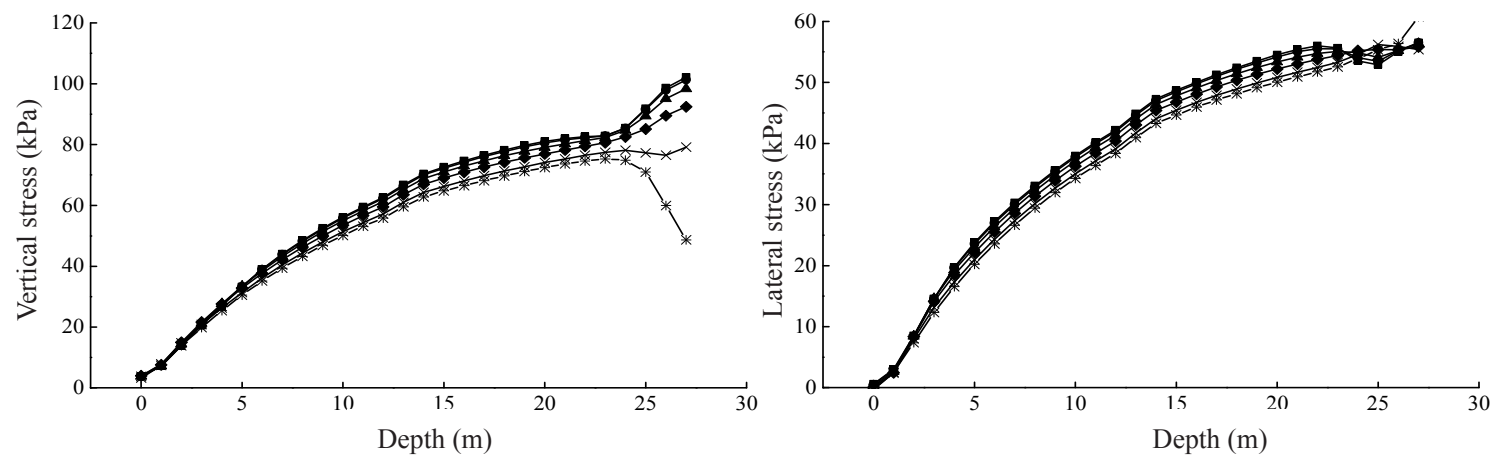

Fig. 3. Stress of the wheat pile: $a$ - at different moisture contents and b-different radius at different moisture contents. 
b

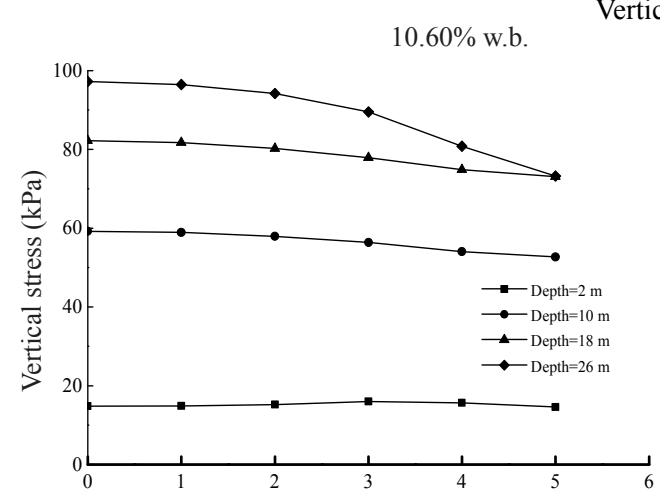

$14.22 \%$ w.b.
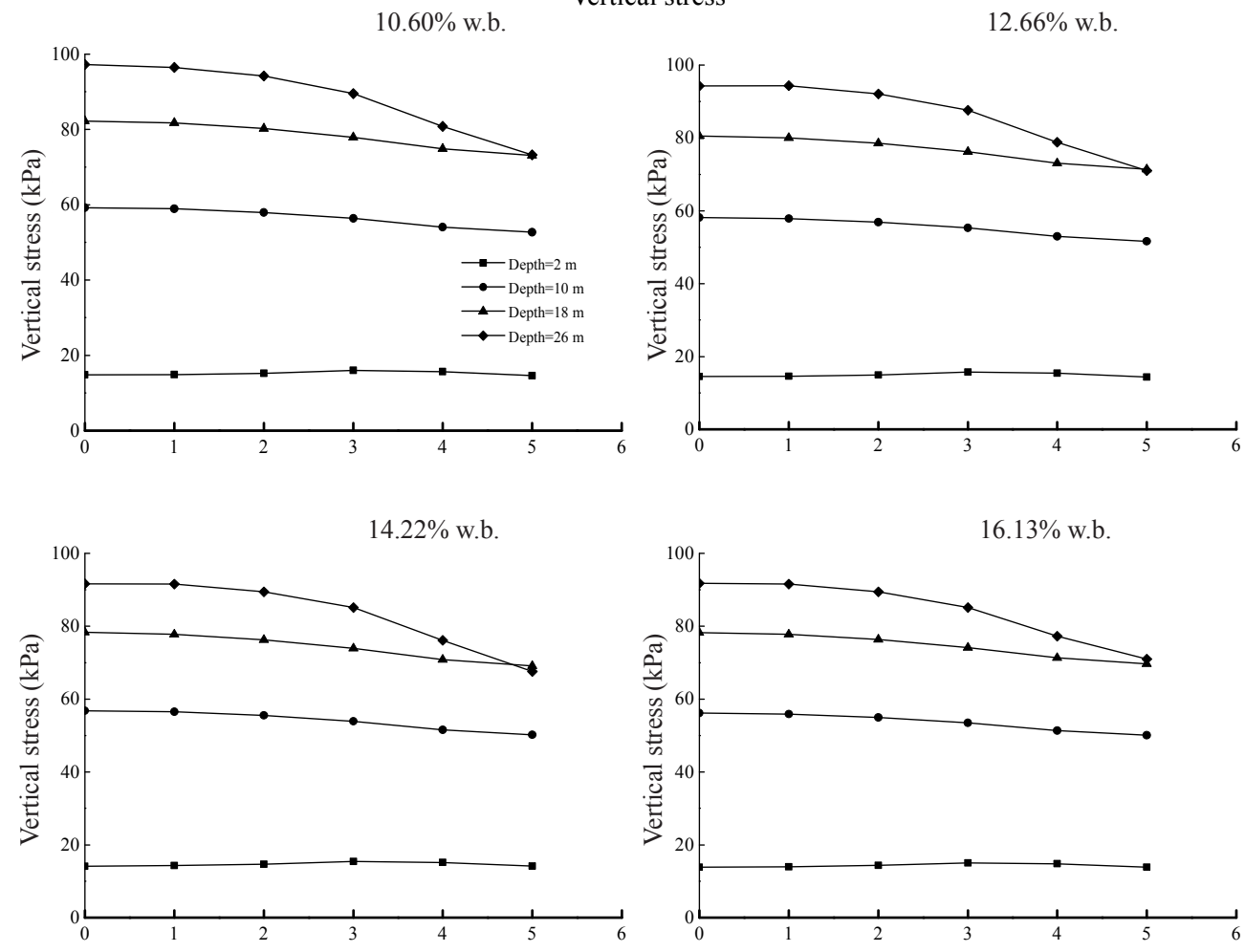

Lateral stress

$10.60 \%$ w.b.

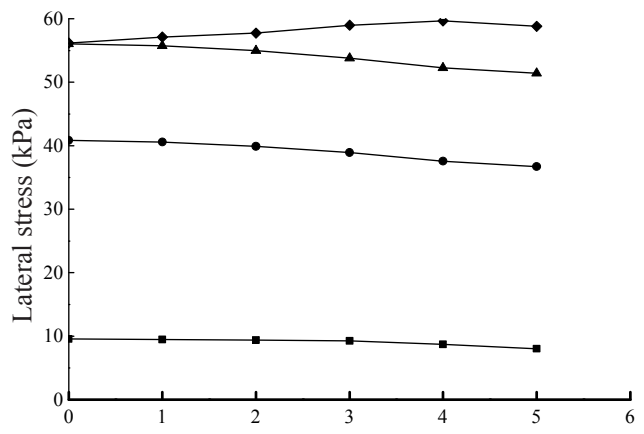

$14.22 \%$ w.b.

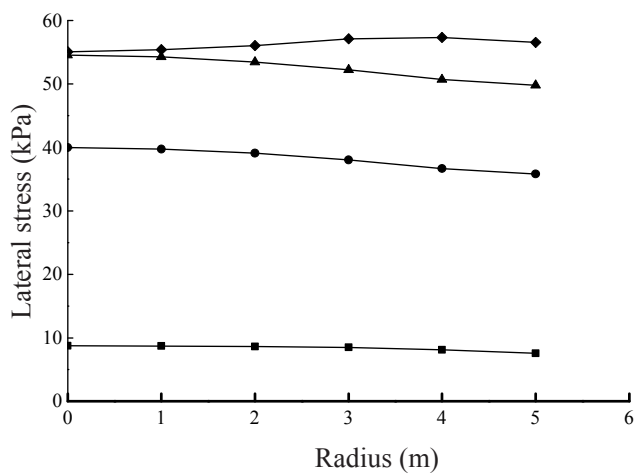

$12.66 \%$ w.b.

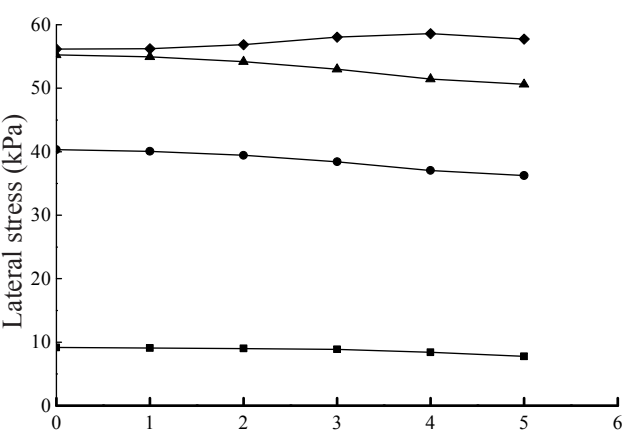

$16.13 \%$ w.b.

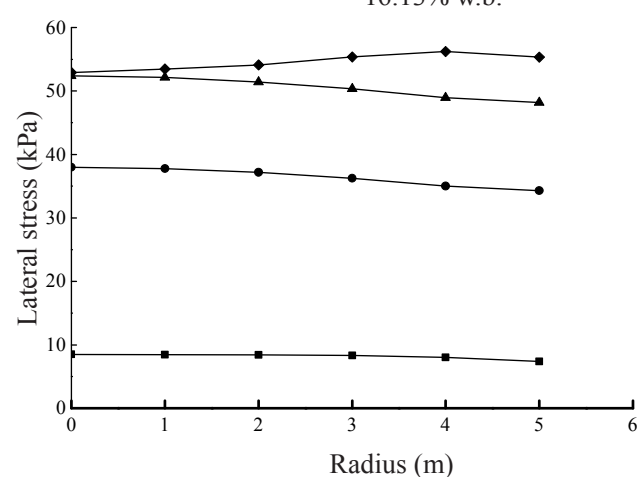

Fig. 3. Continuation. 

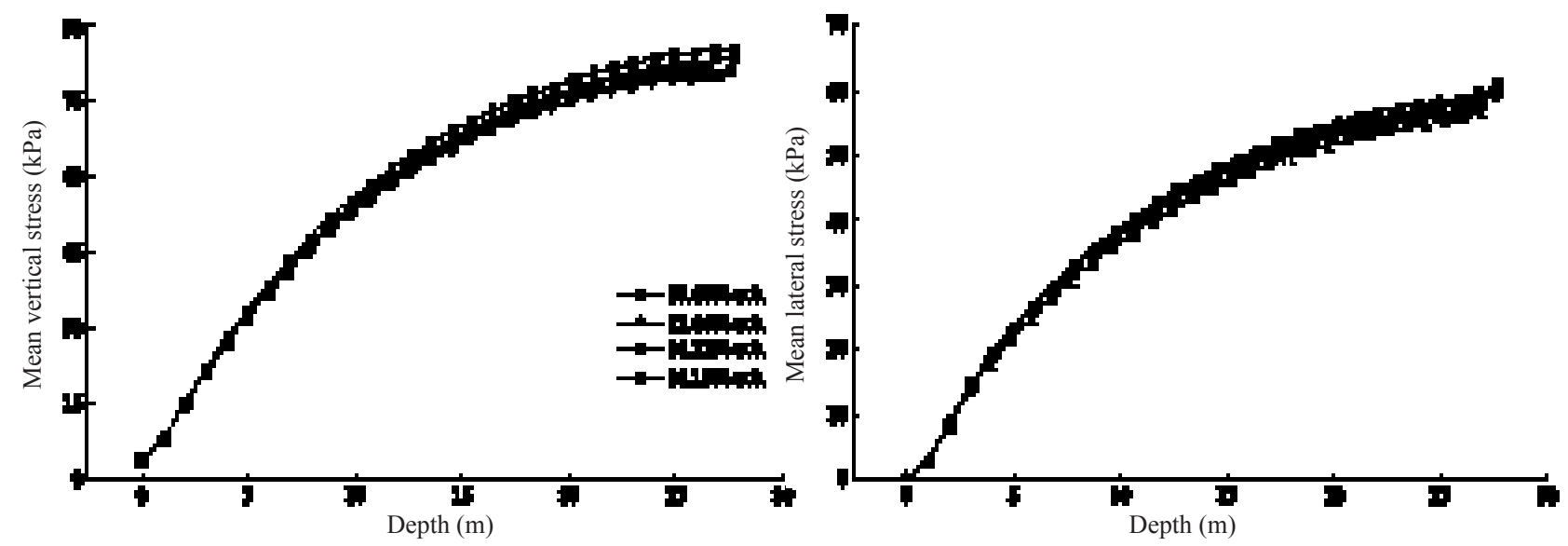

Fig. 4. Variation of the mean stress of different moisture content wheat piles with depth.

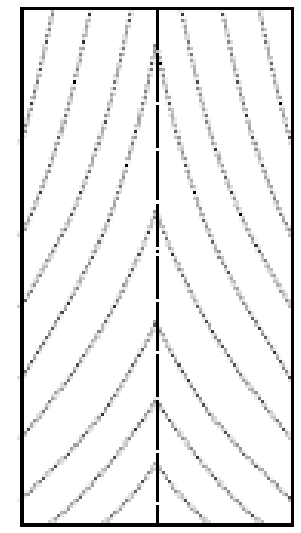

Fig. 5. Principal stress line of the wheat pile in silos.

stress distribution of paddy in the hopper-bottom silo, it was found the vertical and lateral stress acting on the paddy in cylinder part of silo increased with depth of paddy. That was similar with our findings about the mean stress of the wheat in silos. Moreover, Cheng et al. (2017) proposed a model, which consisted of a series of differential equations derived from the force equilibrium on a differential element of grain in the silo, to predict the vertical and lateral pressures in the wheat increased with the grain depth in the cylindrical portion of the hopper-bottom silo, the trends of stress was similar with the trends of the mean vertical and lateral in this article, but a drawback of their researches was the ignorance of the changes of vertical and lateral stresses with increasing radius of silos.

\section{CONCLUSIONS}

Simulations of the vertical and lateral stress distribution have been made in a steel flat bottom silo by the modified Cam-clay model. Based on the tests and the results, we can draw the following conclusions:

1. The vertical stress of wheat piles increased with the increase of the wheat pile depth except the wall-bottom of the silo, and the lateral stress continuously increased expect the center near the bin bottom.
2. While at the same depth and the same moisture content, with the increase of radius, the vertical stress of the wheat pile decreased, and the lateral tress of that grains decreased but increased near the bin bottom.

3. The mean stress of a layer wheat piles increased with the increase of grain depth. While at the same grain depth, the mean lateral stress was negatively correlated with moisture content when the mean vertical stress had no concern with it and all of them approached a plateau value with increasing grain depth at the same moisture content.

Conflict of interest: The Authors do not declare conflict of interest.

\section{REFERENCES}

ASAE Standards, 2001. Moisture measurement-unground grain and seeds. Am. Soc. Agri. Eng., 567-568.

Ayuga F., Moya M., Guaita M., and Aguado P., 2002. Mechanical properties of granular agricultural materials. Trans. ASAE, 45(5), 1569-1578.

Ayuga F., Moya M., Guaita M., and Aguado P., 2006. Mechanical properties of granular agricultural materials, part 2 . Trans. ASABE, 49(2), 479-489.

Bishara A.G., Ayoub S.F., and Mahdy A.S., 1983. Static pressures in concrete circular silos storing granular materials. ACI Jnl., 80(3), 210-216.

Chen X.G., Yang G.H., and Yang X.H., 2011. Soil constitutive models. Beijing: China Water Power Press, 8-92.

Cheng X.D., Lu L.L., and Shi C.X., 2012. The experimental research on friction properties of wheat. J. Chin. Cereals Oils Assoc., 27(4), 15-19.

Cheng X.D., Zhang Q., Shi C.X., and Yan X.J., 2017. Model for the prediction of grain density and pressure distribution in hopper-bottom silos. Biosyst. Eng., 163, 159-166.

Drescher A. and Vgenopoulou I., 1985. A theoretical analysis of channeling in bins and hoppers. Powder Technol., 42(2), 181-191.

Du X.C., Yan X.J., Cheng X.D., Gao M.Y., and Feng J.C., 2017. Model of Density and Pressure Distribution of Paddy in the Hopper-Bottom Silo. J. Chin. Cereals Oils Assoc., 32(5), 102-109. 
FAOSTAT, 2014. Agricultural Data. FAO. Rome: Online at http:// faostat.fao.org/

Gong X.N., 1999. The soil plasticity. Hangzhou: Zhejiang University Press, 246-250.

Goodey R.J., Brown C.J., and Rotter J.M., 2017. Rectangular steel silos: Finite element predictions of filling wall pressures. Eng. Struct., 132, 61-69.

Hatfield F.J. and Bartali E.H., 1988. Static forces and moments in a grain silo. J. Struct. Eng., 114(12), 2814-2819.

Haque E., 2013. Estimating bulk density of compacted grains in storage bins and modifications of Janssen's load equations as affected by bulk density. Food Sci. Nutrition, 1(2), 150-156.

He Z., Rajaram S., Xin Z., and Huang G., 2001. A History of Wheat Breeding in China. CIMMYT, Mexico.

Hibbit, Karlsson, Sorenson Inc., 2001. ABAQUS/Explicit: User's Manual, Version 6.2.

Janssen H.A., 1985. Versuche über getreidedruck in silozellen. Zeitschriff des Vereines Deutscher Ingenieure, 39, 1045-1049.

Jofriet J.C., Lelievre B., and Fwa T.F., 1977. Friction model for finite element analyses of silos. Trans. ASAE, 20(4), 735-740.

Li X.J., Cao Z., Wei Z.Y., and Fen Q.Y., 2011. Equilibrium moisture content and sorption isosteric heats of five wheat varieties in China. J. Stored Prod. Res., 47(1), 39-47.

Luo D., Yao Y.P., and Hou W., 2010. Soil Constitutive Models. China Communications Press, Beijing, 78-82.

Lvin J.B., 1971. Analytical evaluation of pressures of granular materials on silo walls. Powder Technol., 4(5), 280-285.

Mahmoud A. and Abdel-Sayed G., 1981. Loading on shallow cylindrical flexible grain bins. J. Powder Bulk Solids Tech., 5(3), 12-19.
Roberts A.W., 1998. Particle technology-reflections and horizons: An engineering perspective. Chem. Eng. Res. Des., 76(7), 775-796.

Rooda J.E. and Haaker G., 1977. A testing procedure for triaxial tests and a numerical method for the calculation of powder flow properties. Powder Technol., 16(2), 273-280.

Smith D.L.O., 1981. The triaxial load response of grain. Ph.D. Thesis, Iowa State University, Ames, IA, USA.

Su L.Y., 1997. Stress analysis of grain static pressure in vertical silo. J. Zhengzhou Grain College, 18(3), 72-76.

Suebsuk J., Horpibulsuk S., and Liu M.D., 2010. Modified Structured Cam Clay: A generalised critical state model for destructured, naturally structured and artificially structured clays. Comput. Geotech., 37(7-8), 956-968.

Thompson S.A. and Ross I.J., 1983. Compressibility and frictional coefficients of wheat. Trans. ASAE, 26(4), 11711176.

Tripodi M.A., Puri V.M., Manbeck H.B., and Messing G.L., 1994. Triaxial testing of dry, cohesive powder and its application to a modified Cam-clay constitutive model. Powder Technol., 80(1), 35-43.

Vidal P., Gallego E., Guaita M., and Ayuga F., 2008. Finite element analysis under different boundary conditions of the filling of cylindrical steel silos having an eccentric hopper. J. Constr. Steel Res., 64(4), 480-492.

Walters J.K., 1973. A theoretical analysis of stresses in silos with vertical walls. Chem. Eng. Sci., 28(1), 13-21.

Yin W., Lu Y., and Jin Y.O., 2014. Finite element modelling of wall pressures in a cylindrical silo with conical hopper using an Arbitrary Lagrangian-Eulerian formulation. Powder Technol., 257(5), 181-190.

Zhang Q., Puri V.M., and Manbeck H.B., 1986. Determination of elastoplastic constitutive parameters for wheat en masse. Trans. ASAE, 29(6), 1739-1746. 